\title{
A compact QCL spectrometer for mobile, high-precision methane sensing aboard drones
}

\author{
Béla Tuzson $^{1}$, Manuel Graf ${ }^{1}$, Jonas Ravelid ${ }^{1}$, Philipp Scheidegger ${ }^{1}$, André Kupferschmid ${ }^{2}$, Herbert Looser $^{1}$, \\ Randulph Paulo Morales ${ }^{1}$, and Lukas Emmenegger ${ }^{1}$ \\ ${ }^{1}$ Laboratory for Air Pollution/Environmental Technology, Empa - Swiss Federal Laboratory \\ for Materials Science and Technology, Überlandstraße 129, Dübendorf 8600, Switzerland \\ ${ }^{2}$ Transport at Nanoscale Interfaces, Empa - Swiss Federal Laboratory for Materials Science and Technology, \\ Überlandstraße 129, Dübendorf 8600, Switzerland
}

Correspondence: Béla Tuzson (bela.tuzson@empa.ch)

Received: 24 March 2020 - Discussion started: 7 April 2020

Revised: 6 July 2020 - Accepted: 28 July 2020 - Published: 7 September 2020

\begin{abstract}
A compact and lightweight mid-infrared laser absorption spectrometer has been developed as a mobile sensing platform for high-precision atmospheric methane measurements aboard small unmanned aerial vehicles (UAVs). The instrument leverages two recent innovations: a novel segmented circular multipass cell (SC-MPC) design and a power-efficient, low-noise, intermittent continuous-wave (icw) laser driving approach. A system-on-chip hardware control and data acquisition system enables energy-efficient and fully autonomous operation. The integrated spectrometer weighs $2.1 \mathrm{~kg}$ (including battery) and consumes $18 \mathrm{~W}$ of electrical power, making it ideally suited for airborne monitoring applications. Under stable laboratory conditions, the device achieves a precision $(1 \sigma)$ of $1.1 \mathrm{ppb}$ within $1 \mathrm{~s}$ and $0.1 \mathrm{ppb} \mathrm{CH}_{4}$ at $100 \mathrm{~s}$ averaging time. Detailed investigations were performed to identify and quantify the effects of various environmental factors, such as sudden changes in pressure, temperature, and mechanical vibrations, which commonly influence UAV-mounted sensors. The instrument was also deployed in two feasibility field studies: an artificial methane release experiment and a study on vertical profiles in the planetary boundary layer. In both cases, the spectrometer demonstrated its airborne capability of capturing subtle and/or sudden changes in atmospheric $\mathrm{CH}_{4}$ mole fractions and providing real-time data at $1 \mathrm{~s}$ time resolution.
\end{abstract}

\section{Introduction}

Global emissions of methane are continuing to increase, making $\mathrm{CH}_{4}$ a relevant component for managing realistic pathways to mitigate climate change, especially with nearterm benefits (Shindell et al., 2012). However, the accurate quantification of the $\mathrm{CH}_{4}$ budget and its variations still remain challenging, mainly due to uncertainties in $\mathrm{CH}_{4}$ emissions from natural wetlands and fresh waters and not sufficiently constrained partitioning of $\mathrm{CH}_{4}$ emissions by region and processes (Kirschke et al., 2013; Saunois et al., 2016). Therefore, there is a continuing need for technologies that enable the tracking and identification of methane sources at local scale and on a regular basis. In this context, lightweight and high-precision trace gas sensors aboard small unmanned aerial vehicles (UAVs) offer new opportunities for in situ air pollution and emission monitoring (Golston et al., 2017). Combined with fast response, they can provide valuable information about the spatial and temporal variability in emissions regardless of terrain complexity or pollution source characteristics. This significantly extends the scale and the level of detail of measurements compared to those provided by traditional stationary monitoring networks. The potential of this approach is well reflected by the increasing number of reported commercial as well as research-grade sensors and related applications (e.g., Berman et al., 2012; Villa et al., 2016, and references therein). The majority of these solutions are triggered by oil and gas industry fugitive emission monitoring (Nathan et al., 2015; Yang et al., 2018; Golston 
et al., 2018; Fox et al., 2019; Martinez et al., 2020) and, correspondingly, are targeting elevated $\mathrm{CH}_{4}$ concentrations near emission sources. It is, however, more challenging to develop a sensor for the investigation of natural emissions (e.g., O'Connor et al., 2010; DelSontro et al., 2010), which are typically more diffuse and much weaker. Here, we target these more demanding but equally important application areas. Our aim is to drastically reduce the size of conventional lab-based laser spectrometers to an almost handheld device, while maintaining the high precision required for atmospheric methane concentration monitoring. In the following sections, we describe our approach, present the hardware solution, and show the capabilities of the developed $\mathrm{CH}_{4}$ sensor.

\section{Methodology}

\subsection{Spectral selection}

For high-sensitivity methane detection using infrared absorption spectroscopy, there are mainly two suitable spectral regions corresponding to the strong fundamental absorption bands of $\mathrm{C}-\mathrm{H}$ stretching $\left(v_{3}\right.$ at $\left.3.3 \mu \mathrm{m}\right)$ and bending ( $v_{4}$ at $7.7 \mu \mathrm{m})$ modes. Although, the stretching mode contains transition lines of up to 5 times higher intensity compared to the bending band, we still opted for the latter spectral range. This was motivated by two practical factors: (i) distributed feedback quantum cascade lasers (DFB-QCL) with high optical power can readily be used, and (ii) the $P$ branch of the $v_{4}$ band is at the edge of the atmospheric window - i.e., interfering absorption due to water vapor is considerably weaker. This is particularly important in the context of an open-path configuration, i.e., measurements at ambient pressure. Additionally, it is worthwhile to mention that the symmetric stretching vibration band $\left(v_{1}\right)$ of nitrous oxide $\left(\mathrm{N}_{2} \mathrm{O}\right)$ is also located in the vicinity and may be used at a later stage as a secondary tracer. Figure 1 shows the simulated transmittance of ambient air at atmospheric pressure for the spectral range covering the $P$ and $Q$ branch of the $v_{4}$ band of $\mathrm{CH}_{4}$. It might be tempting to select one of the strong absorption features resulting from many overlapping transitions in the $Q$ branch at $7.6 \mu \mathrm{m}$. However, given the narrow tuning range of a DFB laser source, this would make it very difficult to define the intensity baseline for a reliable spectral fitting. This is a consequence of the open-path configuration and the inherent atmospheric pressure-broadening effect, which leads to large absorption features that eventually exceed the tuning range of the laser. In fact, the uncertainty in the baseline retrieval in the open-path system limits the performance in the $Q$ branch, especially when considering other influencing factors such as interferences from pressure-broadened, overlapping absorption features of other atmospheric species and changes in ambient temperature and pressure.
A systematic survey of the $7.7 \mu \mathrm{m}$ spectral region revealed an attractive window in the vicinity of a water absorption line at $1276.62 \mathrm{~cm}^{-1}$ that exhibits a distinctly narrow profile even at ambient pressure (see inset in Fig. 1). According to the HITRAN2016 database (Gordon et al., 2017), this absorption is given by the completely overlapping high$J$ transitions, $15: 0: 15 \leftarrow 16: 1: 16$ and $15: 1: 15 \leftarrow 16$ : $0: 16$. The air-broadening coefficient of these transitions is $0.0064 \mathrm{~cm}^{-1} \mathrm{~atm}^{-1}$, which is about 10 times smaller than for transitions of low- $J$ states. This can be explained by inefficient collisional relaxation due to the wide energy separation $\left(\sim 300 \mathrm{~cm}^{-1}\right)$ for high- $J$ states of $\mathrm{H}_{2} \mathrm{O}$ (Eng et al., 1972; Giesen et al., 1992). Considering the typical energies of translation motion $\left(k_{\mathrm{B}} T \approx 200 \mathrm{~cm}^{-1}\right)$, it is obviously difficult to take up the transition energies from such rotational states. Therefore, the perturbation of these high-rotationalenergy states by collision remains low, which results in lowpressure broadening, so that the $\mathrm{H}_{2} \mathrm{O}$ absorption line at ambient pressure appears as narrow as it would be at $0.1 \mathrm{~atm}$. This aspect has a significant benefit for the spectral analysis: as water is omnipresent, there is always a clear absorption feature that we can use for exact frequency determination, providing a robust anchor for frequency locking by using its spectral position as a control parameter for an active feedback loop on the laser heat sink.

\subsection{Instrumental design}

The instrumental design is strongly driven by the targeted application with special focus on compactness, ruggedness, low power consumption, and weight. These aspects support an open-path approach, where the absorption cell is directly exposed to the atmosphere at ambient pressure, eliminating the need for gas handling and a sampling pump. This considerably reduces weight and power consumption, leads to fast response, and assures low contamination. For high-precision trace gas detection, however, it is necessary to use a multipass cell (MPC) that folds the light path to achieve a sufficiently large signal-to-noise ratio (SNR). This key element often limits miniaturization of laser spectrometers, mainly because of its bulky design. Therefore, we fundamentally reconsidered the MPC concept and recently developed a novel and versatile solution, which is unique in its combination of size, mechanical rigidity, and optical stability. A full description of this design, called segmented circular multipass cell (SC-MPC), is given by Graf et al. (2018). Here, we only recall the main characteristics of the SC-MPC. It consists of a monolithic aluminum ring with a radius of $77.25 \mathrm{~mm}$, containing 65 quadratic, spherically curved segments seamlessly shaped into the ring's inner surface. This geometry supports up to $10 \mathrm{~m}$ optical path length at a total mass of less than $200 \mathrm{~g}$. The SC-MPC has a confocal configuration, and it can thus directly accept the collimated laser beam emitted by the DFB-QCL (Alpes Lasers, Switzerland) encapsulated into a TO-3 housing with embedded collimating optics and thermo- 


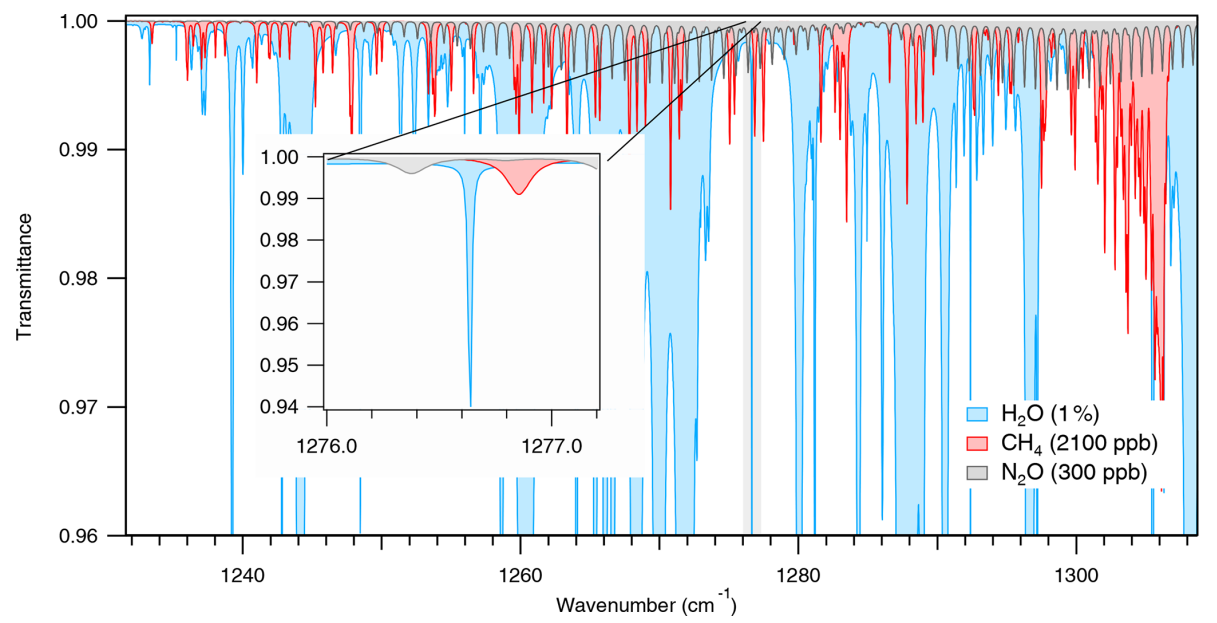

Figure 1. Simulated transmission spectrum of ambient air at atmospheric pressure over an optical path length of $10 \mathrm{~m}$. Only the contributing molecular species, e.g., $\mathrm{H}_{2} \mathrm{O}, \mathrm{CH}_{4}$, and $\mathrm{N}_{2} \mathrm{O}$, with their mean atmospheric abundance are considered. The inset shows the selected spectral window for methane measurements. The water absorption line is markedly narrow, due to a particularly small pressure-broadening coefficient of this transition.

electric cooler (TEC). Furthermore, the cell is largely insensitive to the aiming and coupling of the laser beam, which allows the use of a sturdy, custom-built, three-axis linear stage for the laser source assembly. This module contains an additional TEC connected to a heat sink, which is cooled by forced convection using a fan. After undergoing 65 reflections, the light is focused onto the infrared detector by the specially shaped last segment of the MPC cell. The detector module (VIGO System, Poland) consisting of a multijunction $\mathrm{HgCdTe}$ photodiode (PVM-2TE-8-1×1) with a DCcoupled preamplifier (SIP-DC-15M-TO8-G) is attached to the opposite side of the ring cell (see Fig. 2). The thermal management of the detector is implemented in the same fashion as for the laser, because of the elevated sensitivity of the detector signal to its heat sink temperature (see below). The thermal stability of the detector is crucial for low-drift operation. A $5 \mathrm{~cm}$ long solid-Ge etalon, mounted on a periscopelike mechanical support, can be placed into the MPC to determine the laser tuning-rate. The opto-mechanical setup is thus realized without any beam steering and shaping optics and has an overall weight of $750 \mathrm{~g}$.

Of similar importance are the controlling and driving hardware as well as the data acquisition system. Here, we adopted our intermittent continuous-wave (icw) laser driving concept (Fischer et al., 2014) and developed a current-source-based laser driver optimized for a small footprint and a high temperature stability. The design relies on the concept recently published by Liu et al. (2018) and features three main elements: (i) an active current control, provided by an operationalamplifier-based current regulator; (ii) a high-precision analog pulse generator to generate current pulses with an adjustable amplitude, shape, and width; and (iii) a capacitor that acts as a low-noise power supply, being disconnected from the external source during the operation of the QCL. The whole circuit was optimized for low noise and low temperature sensitivity.

The laser was driven by current pulses of $88 \mu$ duration at $5 \%$ duty cycle, corresponding to 6000 scans per second. Hardware control and DAQ functions are provided by an integrated system-on-chip (SoC; STEMlab 125-14, Red Pitaya, Slovenia) open-source platform featuring an integrated dual-core ARM Cortex A9 processor with Xilinx 7series FPGA logic. The FPGA firmware (VHDL code) and the Linux service routine ( $\mathrm{C}$ code) were custom developed. The SoC GPIOs provide digital triggers required for operating the QCL driver. Further functionalities are realized by a custom-developed extension board with additional ADCs (16 and 24 bits) and DACs. These are used to set and read several temperature values for spectral and diagnostic purposes. The hardware internal communication is based on the inter-integrated circuit $\left(\mathrm{I}^{2} \mathrm{C}\right)$ protocol. The temperature control of the QCL relies on a high-precision thermoelectric cooler (TEC) controller (WTC3243, Wavelength Electronics, USA), while the additional heat sinks (laser and detector) are stabilized by a custom-developed PWM-based controller. The FPGA contains a state machine that is clocked 8 times slower than the sample clock ( $125 \mathrm{MHz})$, which makes routing less critical - i.e., larger data path delays are tolerated. For higher flexibility in data acquisition, several user-defined time windows within a spectral scan are supported. By means of decimation (up to 8), the total acquisition time can be increased, while the surplus samples can be dropped or averaged. The summation of consecutive spectra is implemented as DSP adders and dual-port BRAMs. Port $A$ of the BRAMs is for storing the new sum of the spectra, while port $B$ is for reading the last sum. The spectra are then transferred from the programming logic (PL) via AXI FIFO, DMA, and DDR RAM to the processing system (PS). The DMA is config- 

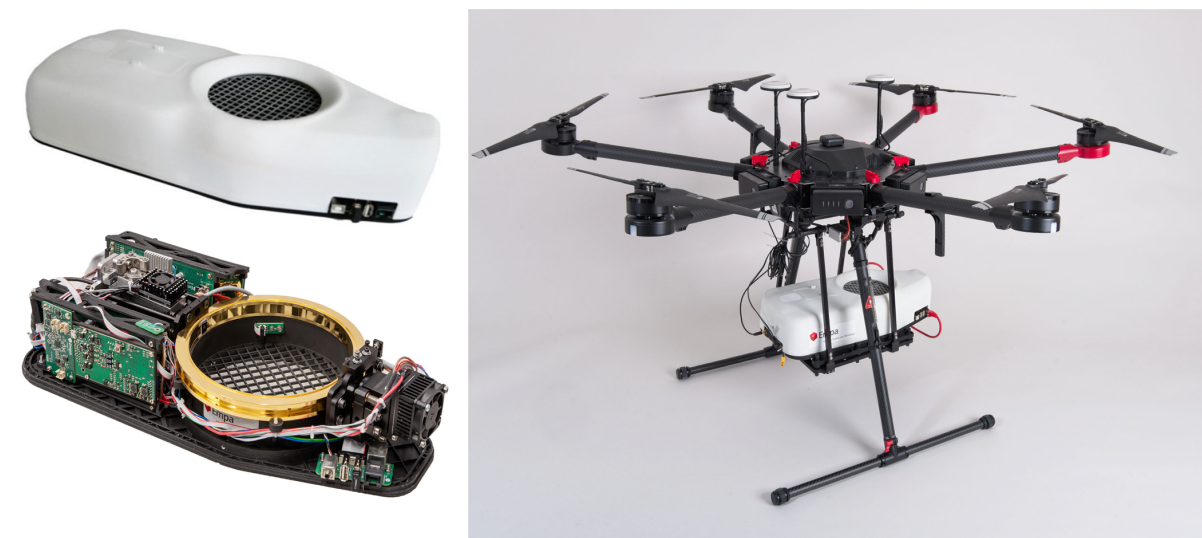

Figure 2. Photograph of the $\mathrm{CH}_{4}$ laser spectrometer with and without the protecting cover (left). The main building blocks are the TO-3packaged QCL installed on a three-axis stage with the additional TEC-stabilized heat sink, the SC-MPC with $10 \mathrm{~m}$ effective path length, the IR detector, also with TEC-stabilized heat sink, and five PCBs incorporating the hardware electronics: an icw laser driver, a DAQ unit with extension board, a power-supply module, the OEM TEC board of the detector, and a custom TEC board for laser and detector heat sinks. The heat sinks of the laser and detector are, in addition, actively air cooled with fans. Picture of the $\mathrm{CH}_{4}$ sensor installed on the hexacopter (Matrice 600, DJI).

ured from a thread started by the Linux service routine. This thread polls the IRQ bit of the DMA status and retriggers the DMA after each interrupt to copy the spectrum to a new destination address within a ring buffer. Whenever a client requests a spectrum, the current data are read from the ring buffer and sent to the client via TCP/IP. Two independent instances of the Linux service routine are started with their own TCP/IP port to assure that the writing and reading of additional signals (e.g., analog and digital inputs) do not interfere with the fast query of spectra.

The detector signal is digitized by the Red Pitaya's onboard ADC with 14-bit resolution and a sampling rate of up to $60 \mathrm{MHz}$, while the FPGA performs the real-time and onboard averaging of the data stream as described above. These data, together with environmental and system log data, are continuously saved on USB flash memory, and, optionally, a copy is sent to a host PC via TCP/IP using wired or wireless connection. Environmental parameters, such as barometric pressure, relative humidity, and ambient temperature are provided by an integrated pressure/humidity/temperature (PHT) sensor (MS8607, Measurement Specialties Inc., USA) situated at the lower edge of the multipass cell (see Fig. 2). Finally, a GPS module (Adafruit Industries, USA) for altitude and position retrieval rounds up the fully autonomous sensor, capable of delivering all the necessary parameters for mobile laser spectroscopy applications. The modular elements are fixed on a mechanically rugged 3D-printed polycarbonate platform with an embedded battery case. A lightweight cover assures protection and insulation of the device (Fig. 2). The overall instrument weights $2.1 \mathrm{~kg}$ including the LiPo battery $(18 \mathrm{~V})$ and has an outdoor average electrical power consumption of $18 \mathrm{~W}$.
For the flight deployments, the device is mounted beneath a hexacopter (Matrice 600, DJI, China) on a bay plate using a gimbal frame with anti-vibration rubber dampers (see Fig. 2). The maximum flight time with the $2 \mathrm{~kg}$ payload is about $20 \mathrm{~min}$. During this period, a wireless bidirectional data link (SkyHopper PRO, Israel) assures real-time access to the raw spectral data and all hardware-related parameters. This allows for real-time spectral fitting and logging, and the user has full control over all the hardware settings and can continuously monitor status of the instrument.

The spectral analysis takes place on the averaged data of 6000 spectra corresponding to $1 \mathrm{~Hz}$ time resolution. A typical transmission spectrum with the associated fitted curves using Voigt profiles is shown in Fig. 3. The spectral line intensity and the broadening parameters are taken from the HITRAN2016 database (Gordon et al., 2017), whereas the gas pressure and temperature are measured.

\section{Results and discussion}

\subsection{Characterization and validation}

The controlled characterization of any open-path spectrometer under representative flight conditions is highly challenging. Therefore, we custom built a small volume $(60 \mathrm{~L})$ climate chamber to have full control over the parameters of interest, such as ambient pressure, temperature, and methane mole fraction (given in units of parts per million or billion ppm or ppb - throughout this paper, representing the number of moles of methane per moles of air). Equipped with a highpower TEC-assembly (with a total of $250 \mathrm{~W}$ cooling power) mounted on a water-cooled heat sink (Lytron Inc., USA), the chamber allows for rapid temperature modulation. A turbu- 


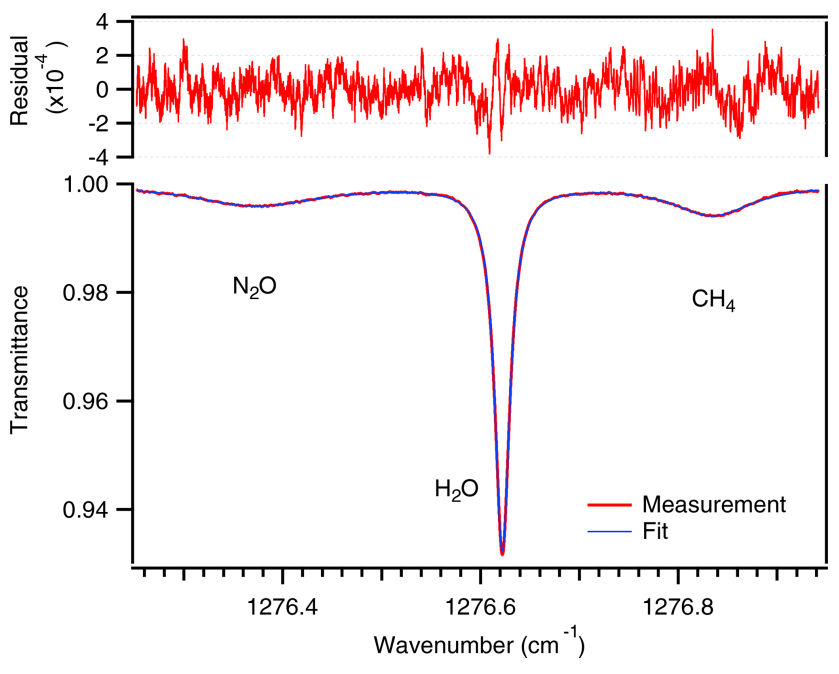

Figure 3. Measured transmission spectrum of ambient air at atmospheric pressure and room temperature recorded at $1 \mathrm{~Hz}$, i.e., averaged over 6000 consecutive single scans. The associated fit (Voigt profile) and the residual plot (top) indicate the high fidelity and quality of the measurement. The laser frequency tuning can be extended to cover a nearby absorption line of $\mathrm{N}_{2} \mathrm{O}$ as well.

lent air circulation can be realized by operating a large radial fan with a flow rate of $55 \mathrm{~m}^{3} \mathrm{~h}^{-1}$. The precision and stability of the spectrometer was assessed within the chamber under continuous purging with air at $2 \mathrm{~L} \mathrm{~min}^{-1}$ from a pressurized air cylinder. During this test, the pressure and the temperature were maintained constant, while the fan was running at full speed. Figure 4a summarizes the results of this measurement. The Allan-Werle variance technique (Werle et al., 1993) applied to the data collected over $1 \mathrm{~h}$ shows that the device achieves a precision of $1.1 \mathrm{ppb}$ within $1 \mathrm{~s}$, corresponding to an absorption noise level of $5.8 \times 10^{-6}$. The sensitivity can be further improved by averaging over at least another $100 \mathrm{~s}$. After this time, the two-sample variance, deviates from the expected $1 / \tau$ line, which indicates that drifts start to dominate the system. Nevertheless, the measurement precision stays below $0.5 \mathrm{ppb}$ for $20 \mathrm{~min}$, corresponding to the duration of a common drone flight. Repeated precision tests indicate a robust stability of the system. The inset in Fig. 4 shows the distribution of the $1 \mathrm{~s}$ Allan-Werle deviations (over 500 values) calculated from data within $200 \mathrm{~s}$ time slots. These records were taken at various days, operating the instrument in the laboratory in open-path configuration and measuring ambient air. The histogram is slightly skewed to the right with the highest count located at $1.2 \mathrm{ppb}$. It shows that the $1 \mathrm{~s}$ noise level is highly reproducible and adds confidence that the $1.5 \mathrm{~h}$ Allan-Werle deviation plot shown in Fig. 4 is representative for the performance of the instrument.

The chamber was also used to determine the response of the spectrometer to $\mathrm{CH}_{4}$ concentration changes. For this purpose, a certified calibration gas with high $\mathrm{CH}_{4}$ concentration (200 ppm $\pm 1 \%$; PanGas, Switzerland) was dynamically di- luted with dry nitrogen $\left(\mathrm{N}_{2}\right)$ in a stepwise fashion using mass flow controllers (see Fig. 4b). The derived linear calibration slope was then used throughout the field campaigns.

A critical and limiting factor for trace gas laser spectroscopy is the appearance of unwanted etalon effects, generally referred to as fringing. This effect is induced by multiple reflections from partially reflecting plane-parallel surfaces (windows, focusing optics) interfering with the main beam. As they differ in phase due to the different path lengths traversed, they can efficiently translate optical frequency into transmitted intensity. This inherent transfer function may exhibit temporal variations due to mechanical vibrations or changes in ambient temperature or pressure. This is especially critical under field conditions, i.e., during flight of the spectrometer, as it tends to impair the measurement. To investigate the impact of such influences, the instrument was repeatedly exposed to sudden pressure and temperature variations generated in the climate chamber. The span of these changes corresponds to situations expected during realistic flight scenarios, e.g., assuming variations in flight altitude up to $500 \mathrm{~m}$ relative to ground, related temperature gradients as well as diurnal temperature changes of up to $10^{\circ} \mathrm{C}$. The results of these experiments are summarized in Fig. 5.

It was found that pressure variations do not influence the performance, as the real-time onboard pressure measurements can be used to fully account for the respective impact on the spectral data, i.e., changes in absorption line width (pressure broadening) as well as changes in the number density of molecules (ideal gas law). In contrast, variations in temperature had a significant effect on the retrieved $\mathrm{CH}_{4}$ mole fraction. This is mainly attributed to changes in the opto-mechanical system. In particular, we found that changes in the retrieved $\mathrm{CH}_{4}$ mole fraction were linearly correlated $\left(23 \mathrm{ppb} \mathrm{K}^{-1}\right)$ with the temperature of the detector module. Therefore, we implemented a TEC-based solution to maintain its heat sink temperature at a constant value of $32 \pm 0.05^{\circ} \mathrm{C}$ even under varying environmental conditions. A further influencing factor - but less significant in magnitude - was the effect of dynamic fringe structures. The broad line profile of the $\mathrm{CH}_{4}$ absorption line was susceptible to slight shifts in the laser emission frequency, which caused subtle baseline variations. Given their complex behavior, it is not possible to fully account for these fringes, which, therefore, may bias the retrieved concentrations. Our strategy to minimize their impact was to implement an active frequency-locking scheme using the water absorption line position as a reference. Thereby, the peak position is continuously determined by real-time spectral fitting and compared to the initial value. Whenever the difference is larger than $\pm 2 \times 10^{-4} \mathrm{~cm}^{-1}$, the laser heat sink temperature is repeatedly adjusted in small steps $(\mathrm{mK})$ with a latency time of $10 \mathrm{~s}$ to compensate this drift. By implementing all the above optimization strategies, the effect of sudden temperature changes on the retrieved $\mathrm{CH}_{4}$ concentration was reduced to about $4 \mathrm{ppb} \mathrm{K}^{-1}$, as indicated in Fig. 5. These perturbations are 


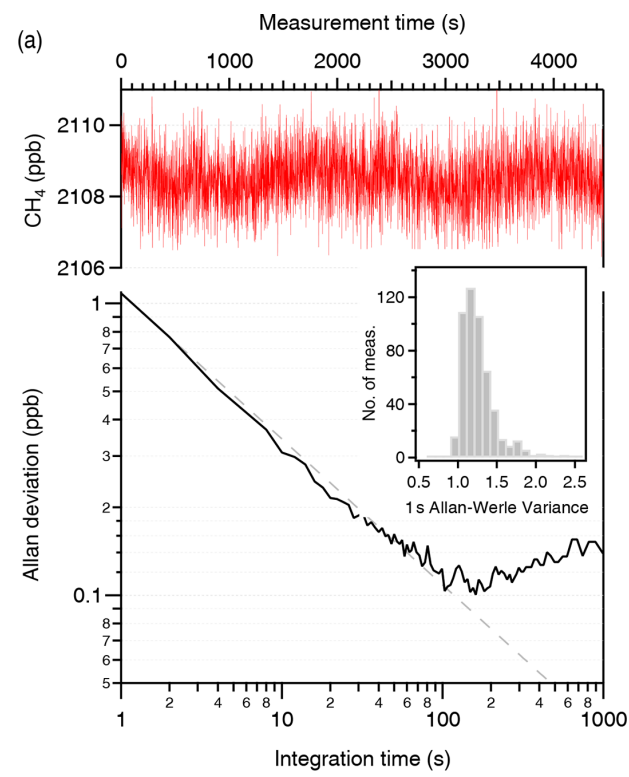

(b)

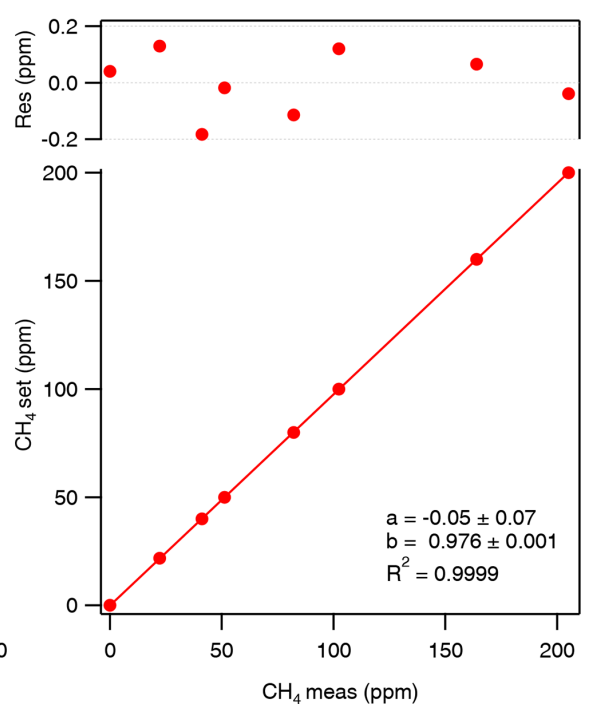

Figure 4. (a) Allan-Werle deviation plot as a function of integration time. The intercept at $1 \mathrm{~s}$ corresponds to $1.1 \mathrm{ppb}$ precision, which continues to improve for $100 \mathrm{~s}$ reaching a value of $0.1 \mathrm{ppb}$. The inset is a histogram plot showing the distribution of the Allan deviation values at $1 \mathrm{~s}$ over multiple measurements. (b) Calibration and linearity test of the $\mathrm{CH}_{4}$ sensor.
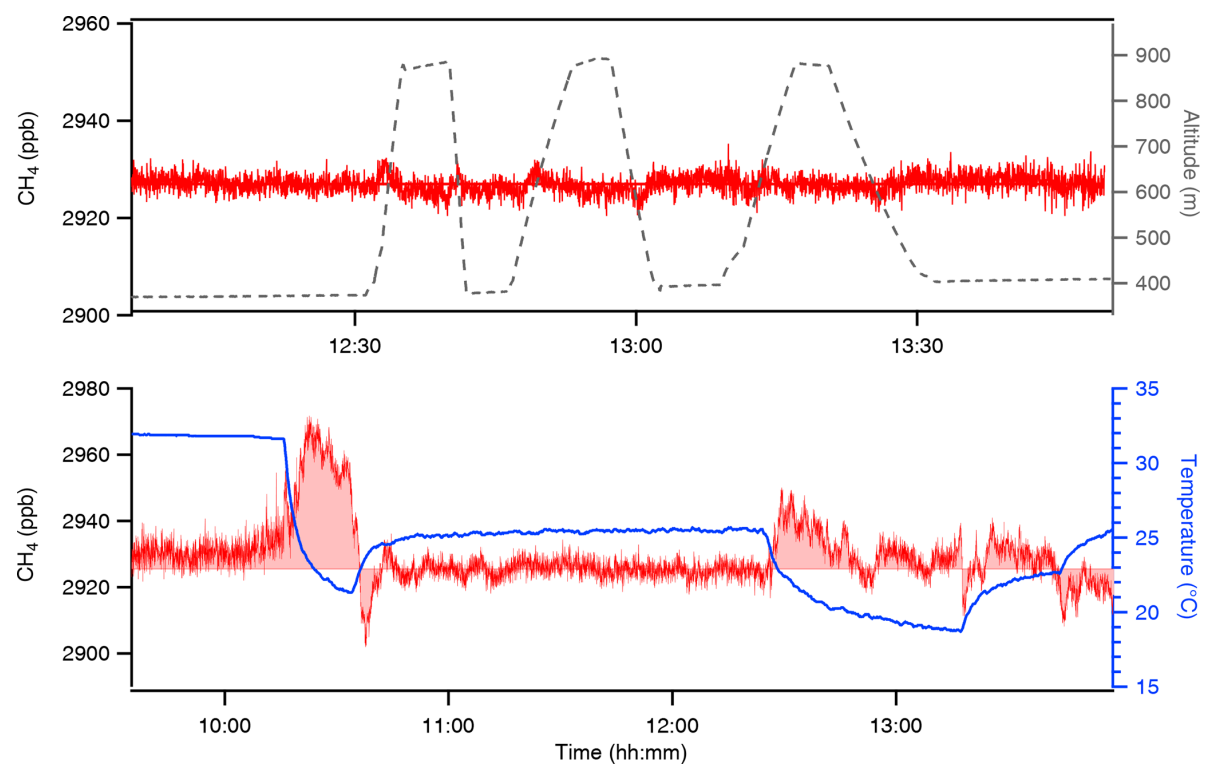

Figure 5. Pressure and temperature dependency of the retrieved $\mathrm{CH}_{4}$ mole fraction values (time zone: $\mathrm{CET}$ ). The induced changes in pressure and temperature correspond to the variations expected during flight, mimicking changes in altitude up to $500 \mathrm{~m}$ and related temperature gradients.

rather of random nature, i.e., difficult to account for, and most likely reflect the susceptibility of all the electronics to abrupt temperature changes. Nevertheless, considering the typical flight scenarios (e.g., emission screening), the temperature changes in such cases are only a few degrees, and correspondingly, the instabilities in the $\mathrm{CH}_{4}$ concentration are expected to stay below $10 \mathrm{ppb}$. Nevertheless, for high-altitude flights, such as planetary boundary layer (PBL) determina- tion, it is definitely advisable to adopt a more elaborated thermal stabilization scheme. In principle, there are two ways to further improve the temperature stability of the instrument: active (e.g., TEC based) and passive. While the former can be very compact, it requires significant electrical power. A passive isolation, although it can efficiently dampen sudden temperature fluctuations, has limited flexibility for the range of supported temperatures. Thus, during the cold season, a 

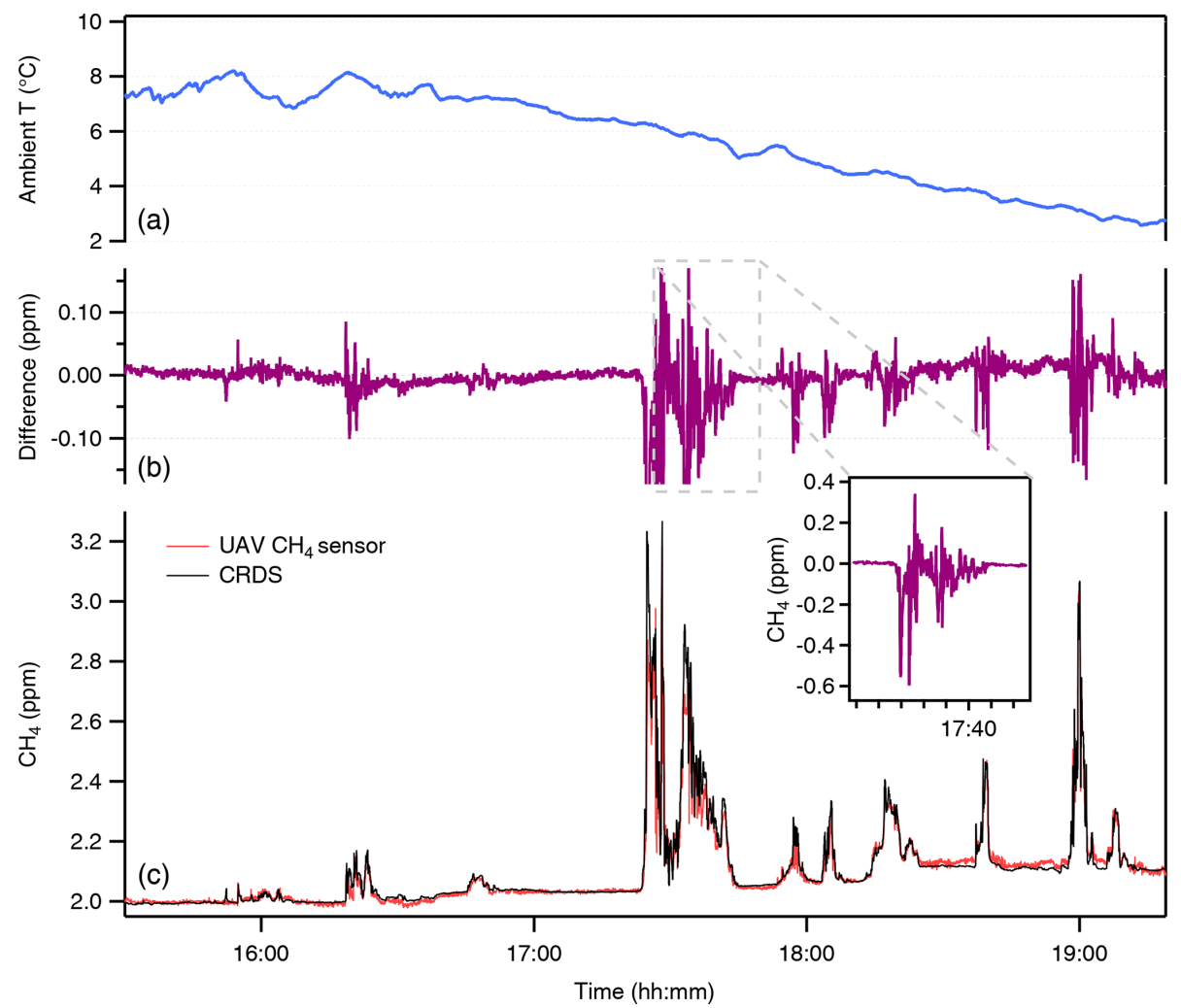

Figure 6. Intercomparison of the $\mathrm{CH}_{4}$ spectrometer with a reference methane analyzer at the NABEL monitoring station (time zone: CET). The device was placed outside, fully exposed to changing environmental conditions, in the proximity of the air inlet located at $2 \mathrm{~m}$ above ground. The recorded time series and the difference in the $\mathrm{CH}_{4}$ concentration between the two analyzers are shown in the (c) and (b) plots The period of large variation in the atmospheric methane concentration is detailed in the inset figure. The variation in the ambient temperature during the measurements is given in the (a) graph.

good isolation can be beneficial, while on hot summer days it can lead to thermal rollover. Lately, we successfully applied a combination of TEC and phase-change material (as thermal buffer medium) solution but with considerable cost of weight and electrical power (Graf et al., 2020). In this case, the instrument demonstrated temperature stabilization in a range of nearly $80^{\circ} \mathrm{C}$. A similar approach could be implemented also for the $\mathrm{CH}_{4}$ spectrometer, when the target application requires the highest precision and accuracy.

Finally, we also tested the influence of mechanical vibrations and air turbulences generated by an operating drone. For this purpose, the instrument was installed on the hexacopter, which was then turned on and off repeatedly to generate typical vibrations and turbulence. It became immediately clear that a direct mechanical contact with the drone body propagates the rotor vibrations onto the spectrometer, generating significant optical noise. Therefore, a gimbal frame with anti-vibration rubber dampers was added beneath the hexacopter, and the $\mathrm{CH}_{4}$ spectrometer was then firmly mounted on this platform. Followup measurements showed no effect on the retrieved methane mole fractions within the measurement precision and natural variability, proving the efficiency of the gimbal system.

\subsection{Field deployments}

Prior to flying aboard a drone, the spectrometer was installed and operated continuously outside in the vicinity of a monitoring station of the Swiss National Air Pollution Monitoring Network (NABEL) in Dübendorf as a final verification for field endurance and long-term stability. Due to the open-path configuration, the measurements were only conducted under good weather conditions to avoid exposure to precipitation. Nevertheless, the instrument was experiencing large diurnal temperature variations (up to $10^{\circ} \mathrm{C}$ difference - see Fig. 6a) wind, and occasionally also direct sunlight. Simultaneously, regular $\mathrm{CH}_{4}$ monitoring measurements were performed with a cavity ring-down spectrometer (G1301, Picarro Inc., USA) installed at the NABEL station. The lateral distance between the air inlet and our $\mathrm{CH}_{4}$ sensor was about $1.5 \mathrm{~m}$. An example of daily $\mathrm{CH}_{4}$ time series is shown in Fig. 6c. The quantum cascade laser absorption spectrometer (QCLAS) device demonstrated stable operation over extended periods of time and successfully captured sudden concentration variations in 

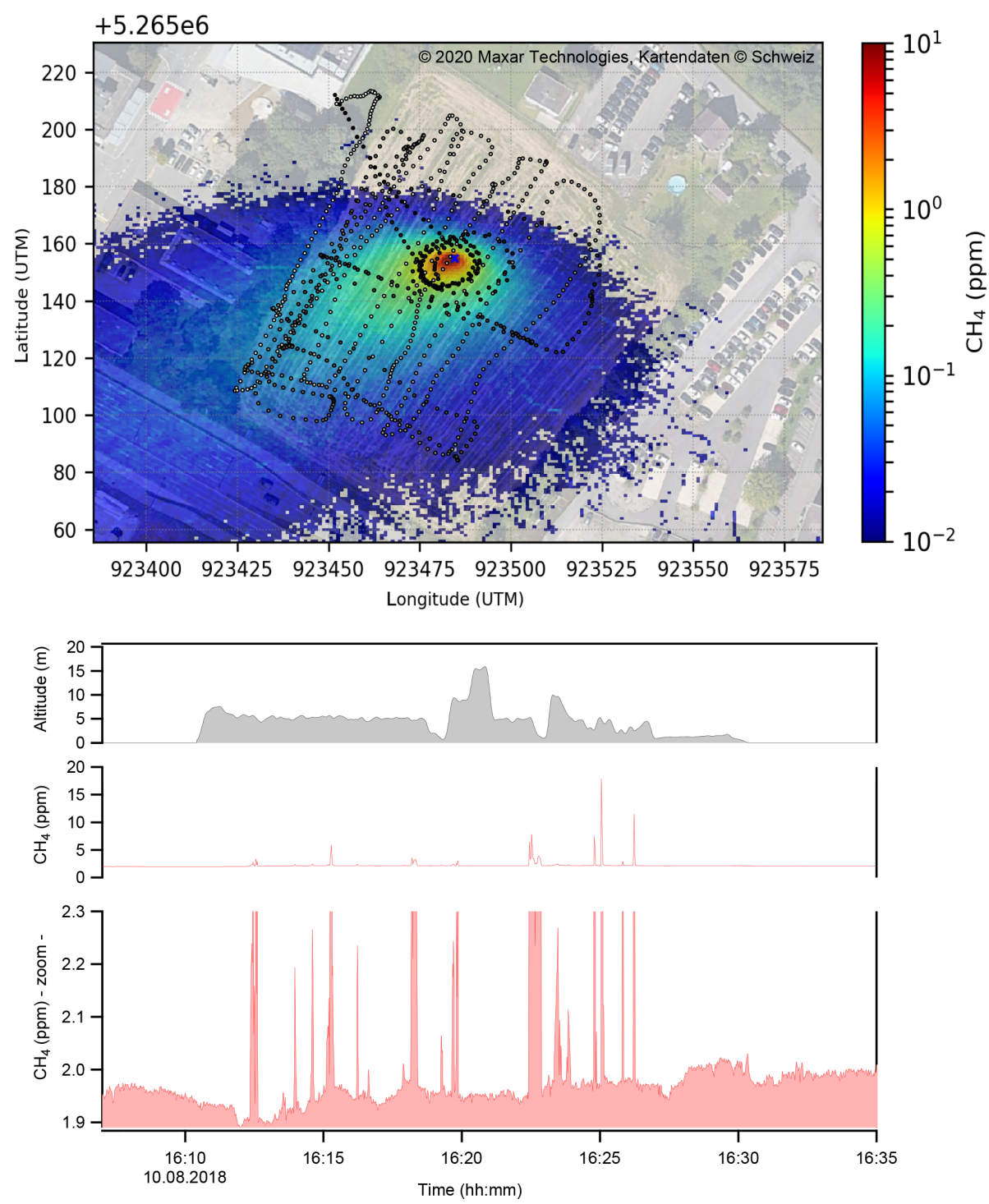

Figure 7. Satellite image of the area used for controlled surface release with the artificial $\mathrm{CH}_{4}$ source, indicated by the blue cross, with the flight tracks superimposed on the simulated footprint emission map (top). Time series (time zone: CET) of the retrieved $\mathrm{CH}_{4}$ concentrations with a zoom-in around the background level (bottom). The in-flight period can be easily deduced from the altitude plot (bottom).

atmospheric methane. The observed spikes were reoccurring regularly in the evening hours, but their origin/source is unknown to us. However, they offered a good opportunity to assess the dynamic response and sensitivity of our $\mathrm{CH}_{4}$ instrument. The observed differences between the two analyzers (see Fig. 6b) are mainly due to the unsynchronized clocks and the difference in response times as well as in sampling strategies, i.e., open and closed path.

\subsubsection{Flying above an artificial source}

For the first test flight we used a small grassland area located near the Empa campus. Here, we installed an artificial $\mathrm{CH}_{4}$ source and released pure methane at a constant flow rate of $10 \mathrm{~L} \mathrm{~min}^{-1}$. To simulate the concentration field of methane and calculate the footprint emission map, the GRAL dispersion model (Oettl et al., 2002) was used. This model computes high-resolution wind fields and turbulence in the presence of 3D obstacles (buildings and vegetation) using a computational fluid dynamics (CFD) approach. The dispersion of pollutants is then computed in a Lagrangian framework by releasing virtual particles at prescribed sources (Anfossi et al., 2006). The forcing for the simulation is obtained from flow fields computed by averaging locally observed meteorological data. In this simulation, meteorological data during the flight were obtained by placing a 3D sonic anemometer (uSonic-3 wind sensor, METEK GmbH, Germany) in the middle of the field. The anemometer, mounted on a $5 \mathrm{~m}$ high mast, sampled the wind direction, ambient temperature, and 

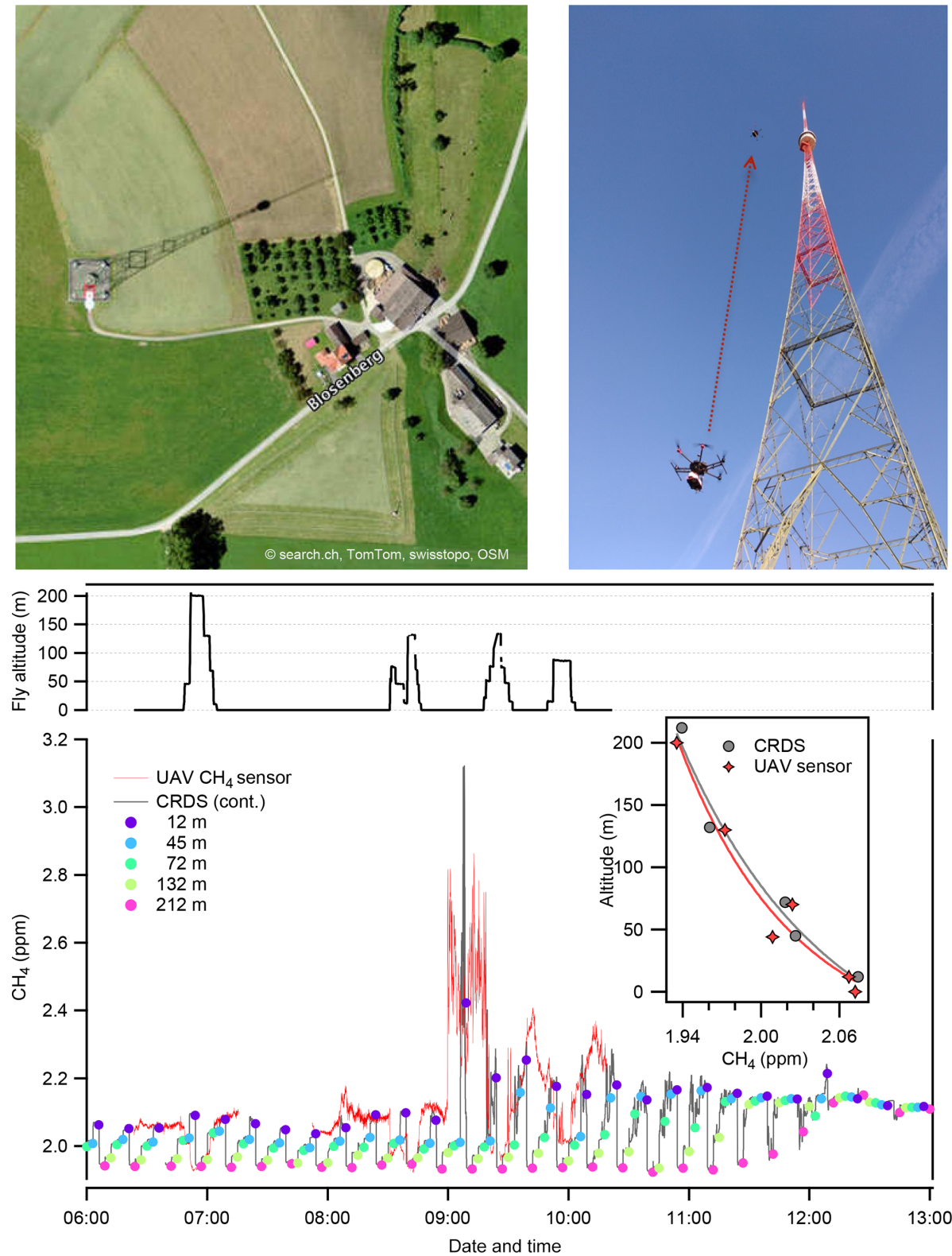

Figure 8. Satellite image of the area used for profiling (top left). Photograph of the drone flying at various heights in the vicinity the radio tower $(212 \mathrm{~m})$ at Beromünster (top right). Vertical profile measurements of atmospheric methane (bottom). The concentration gradient is clearly observable until noon, when the nocturnal boundary layer is broken up by convective vertical mixing. The gray trace represents the continuous, while the colored dots indicate the mean $\mathrm{CH}_{4}$ concentration values at various heights as measured by a ground-based CRDS analyzer. The UAV methane instrument (red trace) performed four flights covering the altitude span between 0 and $200 \mathrm{~m}$. The inset shows the comparison of the profile data collected by the two analyzers. The concentration gradient is well captured in both cases.

wind speeds in the $x, y$, and $z$ directions at $50 \mathrm{~Hz}$. Meteorological data from the anemometer were then averaged to regular 5 min intervals to obtain turbulent parameters such as Obukhov length, friction velocity, and wind speed fluctuations $\left(u^{\prime}, v^{\prime}\right.$, and $\left.w^{\prime}\right)$ and served as input to compute the flow fields. Simulated concentration fields of methane at $5 \mathrm{~min}$ intervals were finally averaged to obtain a footprint emission map of the whole modeling domain.
The $\mathrm{CH}_{4}$ spectrometer was operated prior to the flight for $20 \mathrm{~min}$ on the ground, including warmup time, recording an etalon spectrum, setting up the spectral fit, and initiating the data recording and the wireless communication. Afterwards, the drone was flown at heights above ground ranging from 2 to $15 \mathrm{~m}$ for about $20 \mathrm{~min}$ in the proximity of the artificial methane source (see Fig. 7). The time series recorded along the trajectory intersecting the plume exhibit large spikes re- 
flecting methane enhancements from the release, which is in good qualitative agreement with the GRAL model, which predicted methane concentrations enhancements of up to $10 \mathrm{ppm}$ at $5 \mathrm{~m}$ above the ground.

\subsubsection{Atmospheric profiling}

A challenging but important application for drone-based $\mathrm{CH}_{4}$-sensors is to interrogate the atmospheric boundary layer (ABL) frequently and at multiple locations to provide feedback for ABL model developments. Therefore, we conducted a field test to assess the capability of our $\mathrm{CH}_{4}$ spectrometer to detect small, natural inhomogeneities in the atmospheric methane concentrations at different altitudes throughout the ABL. These field experiments were conducted at Beromünster, which is located in a moderately hilly environment at the southern border of the Swiss Plateau. Here, a former radio tower $\left(47^{\circ} 11^{\prime} 23^{\prime \prime} \mathrm{N}, 8^{\circ} 10^{\prime} 32^{\prime \prime} \mathrm{E}, 212.5 \mathrm{~m}\right.$ tall, base at $797 \mathrm{~m}$ a.s.1.) is equipped with air inlets at 12.5, 44.6, 71.5, 131.6, and $212.5 \mathrm{~m}$, respectively (see Fig. 8). A cavity ring down spectrometer (CRDS; G2401, Picarro Inc., USA) monitors the mole fractions of $\mathrm{CH}_{4}$ at these five different heights sequentially, sampling each height for $3 \mathrm{~min}$ (Satar et al., 2016). The field test took place on a day with stable atmospheric conditions, when methane accumulates during nighttime in a shallow nocturnal boundary layer near the ground. Figure 8 shows the $\mathrm{CH}_{4}$ time series provided by the CRDS analyzer for the selected day. Consistent with our expectations, the data indicate a pronounced gradient among the inlet heights during the time period before sunrise. This concentration buildup then slowly disappears after sunrise due to breakup of the nocturnal boundary layer by convective vertical mixing. The sensor's precision was adequate to easily resolve the vertical gradients of atmospheric methane. The $\mathrm{CH}_{4}$ mole fractions typically varied between 1940 and $2200 \mathrm{ppb}$, with some exceptional cases, when sudden increase in $\mathrm{CH}_{4}$ mole fractions of up to $3200 \mathrm{ppb}$ were observed close to ground over time periods of tens of minutes. These short-term spikes were attributed to pollution events, due to emissions from the farmsteads (ruminants) in the close vicinity $(200 \mathrm{~m})$ of the tower.

\section{Conclusions}

A compact and lightweight laser spectrometer capable of atmospheric $\mathrm{CH}_{4}$ measurements at high sensitivity and time resolution $(1 \mathrm{~Hz})$ was developed to be deployed aboard UAVs. The open-path system has an overall weight of $2.1 \mathrm{~kg}$ (including battery) and an electrical power consumption of $18 \mathrm{~W}$. It can easily be carried by commercial drones, providing unique opportunities for mobile sensing and spatial mapping of $\mathrm{CH}_{4}$ mole fractions at unprecedented precision. The fully autonomous device uses a QCL emitting in the midinfrared at $7.83 \mu \mathrm{m}$, a versatile and robust segmented circu- lar mirror multipass cell (SC-MPC) with $10 \mathrm{~m}$ effective optical path length, and a custom-developed, low-power SoC FPGA-based data acquisition system. The instrument was characterized in the laboratory in terms of precision, linearity, and its dependence on various environmental factors and then validated under field conditions and flown in two different application scenarios. With a precision of $1 \mathrm{ppb} \mathrm{CH}_{4}$ at $1 \mathrm{~Hz}$, the spectrometer represents the very first portable instrument of its class regarding precision, weight, and realtime analysis capabilities. It outperforms existing solutions based on near- and mid-infrared spectroscopy using CRDS (Berman et al., 2012; Martinez et al., 2020) and wavelengthmodulation (Golston et al., 2017) techniques by at least an order of magnitude. The large dynamic range and the fast time resolution of the open-path system can be used to capture transient $\mathrm{CH}_{4}$ concentrations and thus localize and quantify a wide variety of emission sources. Furthermore, the high precision enables measuring vertical profiles of methane, thus creating new opportunities not only for the study of trace gases in the atmospheric boundary layer but also for investigating diffuse natural methane sources. By the time of writing, the device has been deployed in over 60 flights as part of a large field campaign (ROMEO within MEMO $^{2}$ project) measuring emissions from the oil and natural gas infrastructure facilities in Romania.

Data availability. The data used in this paper are available from the corresponding author upon request.

Author contributions. BT and LE conceptualized the project. MG designed and developed the SC-MPC, implemented the environmental sensor and GPS communication scripts on the SoC, and constructed the climate chamber. PS developed and realized the hardware electronics. AK developed the FPGA functionalities for real-time spectral averaging and onboard data saving. HL designed and developed the hardware control and data processing software. JR contributed to the laboratory and field experiments, performed calibration and validation measurements, and flew the drone. RPM performed the simulation of the concentration field of methane and calculated the footprint emission map using the GRAL dispersion model. BT designed, set up and optimized the spectrometer, coordinated and performed laboratory and field experiments, analyzed the data, and prepared the paper with contributions from all authors. LE supervised the project, discussed the results, and reviewed the paper.

Competing interests. The authors declare that they have no conflict of interest.

Acknowledgements. The authors would like to thank all those who have contributed to the $\mathrm{CH}_{4}$ sensor development (Chang Liu, Badrudin Stanicki, Curdin Flepp, Nico Schäfer, Sebastian Humbel) and field testing (Killian Brennan). We thank Beat Schwarzenbach 
for the CRDS data and technical support during the field measurements at the NABEL station in Dübendorf. Markus Leuenberger from University of Bern (Switzerland) is acknowledged for making the CRDS data from Beromünster available. We thank the referees for their kind reviews and helpful suggestions for improving the paper.

Financial support. This research was partially funded by ABB Switzerland. Further funding was provided by H2020 Marie Skłodowska-Curie project Methane goes Mobile - Measurements and Modelling (MEMO2; https://h2020-memo2.eu/), (grant no. 722479). Manuel Graf was supported by the Swiss National Science Foundation (SNSF) (grant no. 157208).

Review statement. This paper was edited by Darin Toohey and reviewed by Alan Fried and David Nelson.

\section{References}

Anfossi, D., Alessandrini, S., Trini Castelli, S., Ferrero, E., Oettl, D., and Degrazia, G.: Tracer dispersion simulation in low wind speed conditions with a new 2D Langevin equation system, Atmos. Environ., 40, 7234-7245, https://doi.org/10.1016/j.atmosenv.2006.05.081, 2006.

Berman, E. S., Fladeland, M., Liem, J., Kolyer, R., and Gupta, M.: Greenhouse gas analyzer for measurements of carbon dioxide, methane, and water vapor aboard an unmanned aerial vehicle, Sensor Actuators B-Chem., 169, 128-135, https://doi.org/10.1016/j.snb.2012.04.036, 2012.

DelSontro, T., McGinnis, D. F., Sobek, S., Ostrovsky, I., and Wehrli, B.: Extreme Methane Emissions from a Swiss Hydropower Reservoir: Contribution from Bubbling Sediments, Environ. Sci. Technol., 44, 2419-2425, https://doi.org/10.1021/es9031369, 2010.

Eng, R. S., Calawa, A. R., Harman, T. C., Kelley, P. L., and Javan, A.: Collisional narrowing of infrared watervapor transitions, Appl. Phys. Lett., 21, 303-305, https://doi.org/10.1063/1.1654387, 1972.

Fischer, M., Tuzson, B., Hugi, A., Bronnimann, R., Kunz, A., Blaser, S., Rochat, M., Landry, O., Muller, A., and Emmenegger, L.: Intermittent operation of QC-lasers for midIR spectroscopy with low heat dissipation: Tuning characteristics and driving electronics, Opt. Express, 22, 7014-7027, https://doi.org/10.1364/OE.22.007014, 2014.

Fox, T., Barchyn, T., Risk, D., Ravikumar, A., and Hugenholtz, C.: A review of close-range and screening technologies for mitigating fugitive methane emissions in upstream oil and gas, Environ. Res. Lett., 14, 053002, https://doi.org/10.1088/17489326/ab0cc3, 2019.

Giesen, T., Schieder, R., Winnewisser, G., and Yamada, K.: Precise measurements of pressure broadening and shift for several $\mathrm{H}_{2} \mathrm{O}$ lines in the $v_{2}$ band by argon, nitrogen, oxygen, and air, J. Mol. Spectrosc., 153, 406-418, https://doi.org/10.1016/00222852(92)90485-7, 1992.

Golston, L. M., Tao, L., Brosy, C., Schäfer, K., Wolf, B., McSpiritt, J., Buchholz, B., Caulton, D. R., Pan, D., Zondlo, M. A., Yoel, D.,
Kunstmann, H., and McGregor, M.: Lightweight mid-infrared methane sensor for unmanned aerial systems, Appl. Phys. B, 123, 170, https://doi.org/10.1007/s00340-017-6735-6, 2017.

Golston, L. M., Aubut, N. F., Frish, M. B., Yang, S., Talbot, R. W., Gretencord, C., McSpiritt, J., and Zondlo, M. A.: Natural Gas Fugitive Leak Detection Using an Unmanned Aerial Vehicle: Localization and Quantification of Emission Rate, Atmosphere, 9, 333, https://doi.org/10.3390/atmos9090333, 2018.

Gordon, I. E., Rothman, L. S., Hill, C., Kochanov, R. V., Tan, Y., Bernath, P. F., Birk, M., Boudon, V., Campargue, A., Chance, K. V., Drouin, B. J., Flaud, J. M., Gamache, R. R., Hodges, J. T., Jacquemart, D., Perevalov, V. I., Perrin, A., Shine, K. P., Smith, M. A. H., Tennyson, J., Toon, G. C., Tran, H., Tyuterev, V. G., Barbe, A., Császár, A. G., Devi, V. M., Furtenbacher, T., Harrison, J. J., Hartmann, J. M., Jolly, A., Johnson, T. J., Karman, T., Kleiner, I., Kyuberis, A. A., Loos, J., Lyulin, O. M., Massie, S. T., Mikhailenko, S. N., Moazzen-Ahmadi, N., Müller, H. S. P., Naumenko, O. V., Nikitin, A. V., Polyansky, O. L., Rey, M., Rotger, M., Sharpe, S. W., Sung, K., Starikova, E., Tashkun, S. A., Auwera, J. V., Wagner, G., Wilzewski, J., Wcislo, P., Yu, S., and Zak, E. J.: The HITRAN2016 molecular spectroscopic database, J. Quant. Spectrosc. Ra. Trans., 203, 3-69, https://doi.org/10.1016/j.jqsrt.2017.06.038, 2017.

Graf, M., Emmenegger, L., and Tuzson, B.: Compact, circular, and optically stable multipass cell for mobile laser absorption spectroscopy, Opt. Lett., 43, 2434-2437, https://doi.org/10.1364/OL.43.002434, 2018.

Graf, M., Scheidegger, P., Kupferschmid, A., Looser, H., Peter, T., Dirksen, R., Emmenegger, L., and Tuzson, B.: Compact and Lightweight Mid-IR Laser Spectrometer for Balloon-borne Water Vapor Measurements in the UTLS, Atmos. Meas. Tech. Discuss., https://doi.org/10.5194/amt-2020-243, in review, 2020.

Kirschke, S., Bousquet, P., Ciais, P., Saunois, M., Canadell, J. G., Dlugokencky, E. J., Bergamaschi, P., Bergmann, D., Blake, D. R., Bruhwiler, L., Cameron-Smith, P., Castaldi, S., Chevallier, F., Feng, L., Fraser, A., Heimann, M., Hodson, E. L., Houweling, S., Josse, B., Fraser, P. J., Krummel, P. B., Lamarque, J.F., Langenfelds, R. L., Le Quéré, C., Naik, V., O’Doherty, S., Palmer, P. I., Pison, I., Plummer, D., Poulter, B., Prinn, R. G., Rigby, M., Ringeval, B., Santini, M., Schmidt, M., Shindell, D. T., Simpson, I. J., Spahni, R., Steele, L. P., Strode, S. A., Sudo, K., Szopa, S., van der Werf, G. R., Voulgarakis, A., van Weele, M., Weiss, R. F., Williams, J. E., and Zeng, G.: Three decades of global methane sources and sinks, Nat. Geosci., 6, 813, https://doi.org/10.1038/ngeo1955, 2013.

Liu, C., Tuzson, B., Scheidegger, P., Looser, H., Bereiter, B., Graf, M., Hundt, M., Aseev, O., Maas, D., and Emmenegger, L.: Laser driving and data processing concept for mobile trace gas sensing: Design and implementation, Rev. Sci. Instrum., 89, 065107 , https://doi.org/10.1063/1.5026546, 2018.

Martinez, B., Miller, T. W., and Yalin, A. P.: Cavity Ring-Down Methane Sensor for Small Unmanned Aerial Systems, Sensors, 20, 454, https://doi.org/10.3390/s20020454, 2020.

Nathan, B. J., Golston, L. M., O’Brien, A. S., Ross, K., Harrison, W. A., Tao, L., Lary, D. J., Johnson, D. R., Covington, A. N., Clark, N. N., and Zondlo, M. A.: Near-Field Characterization of Methane Emission Variability from a Compressor Station Using a Model Aircraft, Environ. Sci. Technol., 49, 7896-7903, https://doi.org/10.1021/acs.est.5b00705, 2015. 
O’Connor, F. M., Boucher, O., Gedney, N., Jones, C. D., Folberth, G. A., Coppell, R., Friedlingstein, P., Collins, W. J., Chappellaz, J., Ridley, J., and Johnson, C. E.: Possible role of wetlands, permafrost, and methane hydrates in the methane cycle under future climate change: A review, Rev. Geophys., 48, RG4005, https://doi.org/10.1029/2010RG000326, 2010.

Oettl, D., Sturm, P. J., Bacher, M., Pretterhofer, G., and Almbauer, R. A.: A simple model for the dispersion of pollutants from a road tunnel portal, Atmos. Environ., 36, 2943-2953, https://doi.org/10.1016/S1352-2310(02)00254-6, 2002.

Satar, E., Berhanu, T. A., Brunner, D., Henne, S., and Leuenberger, M.: Continuous $\mathrm{CO}_{2} / \mathrm{CH}_{4} / \mathrm{CO}$ measurements (2012-2014) at Beromünster tall tower station in Switzerland, Biogeosciences, 13, 2623-2635, https://doi.org/10.5194/bg-13-2623-2016, 2016.

Saunois, M., Bousquet, P., Poulter, B., Peregon, A., Ciais, P., Canadell, J. G., Dlugokencky, E. J., Etiope, G., Bastviken, D., Houweling, S., Janssens-Maenhout, G., Tubiello, F. N., Castaldi, S., Jackson, R. B., Alexe, M., Arora, V. K., Beerling, D. J., Bergamaschi, P., Blake, D. R., Brailsford, G., Brovkin, V., Bruhwiler, L., Crevoisier, C., Crill, P., Covey, K., Curry, C., Frankenberg, C., Gedney, N., Höglund-Isaksson, L., Ishizawa, M., Ito, A., Joos, F., Kim, H.-S., Kleinen, T., Krummel, P., Lamarque, J.-F., Langenfelds, R., Locatelli, R., Machida, T., Maksyutov, S., McDonald, K. C., Marshall, J., Melton, J. R., Morino, I., Naik, V., O’Doherty, S., Parmentier, F.-J. W., Patra, P. K., Peng, C., Peng, S., Peters, G. P., Pison, I., Prigent, C., Prinn, R., Ramonet, M., Riley, W. J., Saito, M., Santini, M., Schroeder, R., Simpson, I. J., Spahni, R., Steele, P., Takizawa, A., Thornton, B. F., Tian, H., Tohjima, Y., Viovy, N., Voulgarakis, A., van Weele, M., van der Werf, G. R., Weiss, R., Wiedinmyer, C., Wilton, D. J., Wiltshire, A., Worthy, D., Wunch, D., Xu, X., Yoshida, Y., Zhang, B., Zhang, Z., and Zhu, Q.: The global methane budget 2000-2012, Earth Syst. Sci. Data, 8, 697-751, https://doi.org/10.5194/essd-8-697-2016, 2016.
Shindell, D., Kuylenstierna, J., Vignati, E., Van Dingenen, R., Amann, M., Klimont, Z., Anenberg, S., Muller, N., JanssensMaenhout, G., Raes, F., Schwartz, J., Faluvegi, G., Pozzoli, L., Kupiainen, K., Höglund-Isaksson, L., Emberson, L., Streets, D., Ramanathan, V., Hicks, K., Oanh, N., Milly, G., Williams, M., Demkine, V., and Fowler, D.: Simultaneously mitigating near-term climate change and improving human health and food security, Science, 335, 183-189, https://doi.org/10.1126/science.1210026, 2012.

Villa, T., Gonzalez, F., Miljevic, B., Ristovski, Z. D., and Morawska, L.: An overview of small unmanned aerial vehicles for air quality measurements: Present applications and future prospectives, Sensors (Switzerland), 16, 1072, https://doi.org/10.3390/s16071072, 2016.

Werle, P., Mücke, R., and Slemr, F.: The limits of signal averaging in atmospheric trace-gas monitoring by tunable diode-laser absorption spectroscopy (TDLAS), Appl. Phys. B, 57, 131-139, https://doi.org/10.1007/BF00425997, 1993.

Yang, S., Talbot, R. W., Frish, M. B., Golston, L. M., Aubut, N. F., Zondlo, M. A., Gretencord, C., and McSpiritt, J.: Natural Gas Fugitive Leak Detection Using an Unmanned Aerial Vehicle: Measurement System Description and Mass Balance Approach, Atmosphere, 9, 1072, https://doi.org/10.3390/atmos9100383, 2018. 